\title{
What are the rules for biofuel carbon accounting?
}

\author{
Eric P Johnson ${ }^{1, *}$ \\ ${ }^{1}$ Atlantic Consulting, Gattikon, Switzerland \\ * Corresponding author. Tel: +41 44772 1079, E-mail: ejohnson@ecosite.co.uk
}

\begin{abstract}
Most quantitative assessments of biomass fuels or biofuels assume that bioenergy is inherently carbon neutral, that biogenic emissions of carbon dioxide should be excluded from a carbon footprint. This 'carbon neutral' assumption makes an enormous difference in carbon accounts and in the policies that those accounts would suggest. For instance, if harvested logs burnt as fuel are considered carbon neutral, their carbon footprint is far lower than that of natural gas. However, if the logs' biogenic carbon emissions are counted, then their carbon footprint is much higher than gas's. Moreover, this can lead to absurd conclusions. If carbon neutrality is presumed, it makes no difference to a carbon footprint if a forest is standing or if it has been chopped down for fuel wood. Since the mid-1990s, some researchers have contradicted the 'carbon neutral' assumption, and their view that biogenic emissions should be counted has begun to attract significant attention of policy makers. This paper reviews the history and current state of biogenic-carbon accounting rules, including the ISO/CEN rules being developed under the EU Renewable Energy Directive. Without taking sides, it will define the debate for researchers and policy-makers, reflect on its significance and suggest possible means of resolution.
\end{abstract}

Keywords: biofuels, carbon accounting, carbon neutral

\section{Introduction: The premise of carbon neutral}

In the fields of life-cycle assessment and carbon footprinting, biofuels traditionally have been considered as inherently carbon neutral: biogenic emissions of carbon dioxide are excluded from the inventory or footprint. Two landmark studies in the field, (Argonne Labs GREET) and (Joint Research Centre of the EU Commission, EUCAR et al. 2008) take this position as given, and many other studies follow their leads.

More recently, however, some researchers have begun to question this approach. Probably the best-known are (Searchinger, Hamburg et al. 2009), but the issue had already been raised by others, namely (Rabl, Benoist et al. 2007) and (Johnson 2009). More recently (Manomet Center for Conservation Sciences 2010) published a large report that questioned the 'carbon-neutralassumption'. The International Energy Agency's (IEA) Bioenergy Task 38 group, 'Greenhouse Gas Balances of Biomass and Bioenergy Systems', has also raised questions ${ }^{1}$, particularly from (Berntsen and Peters 2010) and (Cowie 2010).

Some regulators appear to be taking these questions seriously. The (Manomet Center for Conservation Sciences 2010) report was commissioned by and adopted by the US Commonwealth of Massachusetts with respect to its regulation of biomass-fueled power plants. Presumably Task 38 is being taken seriously by IEA member governments, and at the United Nations level, the idea of that REDD (Reducing Emissions from Deforestation and Forest Degradation) is generally desirable seems to be undisputed.

Furthermore, the issue has come into the domain of standards organizations. Technical Committee 383 at CEN is working on norms in this area, as is ISO Project Committee 248 (of which the author is a member).

\footnotetext{
${ }^{1}$ See a March 2010 conference record at http://ieabioenergy-task38.org/workshops/brussels2010/
} 
And what is the question? Primarily it is this: should biofuels be considered inherently carbon neutral? The first-generation position was yes (although it was more an assumption than an answer to a question); the emerging position is at minimum not an automatic yes, but a definitive second-generation answer is yet to be determined fully.

The importance of this question, in environmental terms, is very high. Biofuels are clearly the main solution proposed by governments to the twin problems of climate change and energy security. Non-bio, non-fossil energies - such as solar, tidal and wind - are and will for the medium term be marginal contributors, whereas biofuels are aimed at taking, for instance, a $20 \%$ share of the EU energy mix by 2020. If these biofuels turn out to be, relative to conventional fossil fuels, carbon negative rather than positive, then their subsidies will not only have cost billions ${ }^{2}$, they will also have worsened rather than mitigated global warming!

This paper is meant to elaborate the issue from the perspective of carbon footprinting. After a brief statement of method, it presents results, i.e. characterization of the 'carbon neutral' question from six different methodological perspectives. It concludes with findings and suggestions for further study.

\section{Method}

The author has reviewed the literature as well as the political and the standards documentation, and then refracted these in the light of carbon-footprint methods.

\section{Results: how the 'carbon neutral' question can be categorised}

Using the method of carbon footprinting or life-cycle assessment, the question of biofuel carbon neutrality can be characterized in six ways, which are described in the following six subsections.

\subsection{Boundary of the system}

In impact analyses such as life-cycle assessment or carbon footprinting, for a full life-cycle the ideal boundary is 'cradle-to-grave', i.e. from the environment to the environment. As the ISO standard for life cycle assessment (ISO 2006, section 5.2.3) expresses it: "Ideally, the product system should be modelled in such a manner that inputs and outputs at its boundary are elementary flows." In other words, the life-cycle boundary begins and ends with human intervention. Purely natural processes - biogenic as opposed to anthropogenic - are not included.

Growing of crops, say as feedstock for fuel, is of course an anthropogenic activity. Fields of rapeseed, soybeans or wheat do not spring up on their own. The carbon released in creating and maintaining such fields (so-called 'land-use change' emissions), as well as the carbon emitting in cropping them, is included in current assessments; however, the carbon taken in during a growing season is netted out against the carbon emitted in combustion. And this seems consistent with the boundary definition above.

But what about a natural forest? If human activity was not needed to create it, why should its carbon emitted in combustion - clearly a human activity - be netted against carbon taken from the atmosphere to create the trees? This seems inconsistent with the human/nature

\footnotetext{
${ }^{2}$ OECD countries' annual subsidy of biofuels in 2007 was estimated at about $\$ 15$ billion.
} 
boundary applied to other assessments. To be consistent, human harvesting of natural forests should not be netted against their biogenic creation. (Plantations are a different matter; they are created by humans.) This would be consistent with how harvest of other natural resources - say, oil or limestone - is treated in LCA and footprints. Harvest of these is not netted against their creation.

\subsection{Temporal definition of the system}

In common usage, the terms biofuels and renewables are actually misnomers. Surely conventional oil and gas, which are derived from long-dead plants and animals - are biofuels? And solar power, as astrophysicists tell us, is not renewable. The sun is does not recycle its hydrogen, and in some millions of years will burn itself out. These observations are more than just amusing. They point out the temporal boundaries placed implicitly on LCAs and carbon footprints. To be careful in carbon accounting, analyses should recognize such temporal boundaries explicitly.

Also, researchers should consider the theoretical basis for granting carbon credits to biofuels, yet not doing so to fossil-biofuels. At present this appears to be done out of intuition - not out of thought-through reasoning. The reasoning should be developed, or the practice should be ended.

People often justify 'carbon neutrality' of biofuels by saying: 'the tree will grow back'. If it grows back in 10 minutes, fine. But what if if grows back in 10 years, or 100 years? Surely there is an inflection point (and it could be calculated) as to when the grow-back timing changes from favourable to unfavourable.

\subsection{Shadow/alternative/counterfactual scenarios}

If we had not grown a crop to be used as fuel, what would have happened to the carbon balance then?

This idea of a 'shadow' or alternative scenario, sometimes called 'the counterfactual', is not present in most studies of biofuels. In a 2008 survey of over 100 publications by 56 researchers about solid biomass fuels (Johnson 2009), not one of them postulated a shadow scenario. After extensive work on liquid biofuels over the past eight years, the author is aware of only two researchers who have applied it in this area: (Joint Research Centre of the EU Commission, EUCAR et al. 2006) and (Heinen and Johnson 2008).

Broader research by (Manomet Center for Conservation Sciences 2010) and IEA Task 38 suggest that shadow scenarios should be standard, not the exception. Moreover, the idea of REDD (Reducing Emissions from Deforestation and Forest Degradation) in the UNFCCC and the idea of 'additionality' in the Clean Development Mechanism (CDM) and elsewhere, both suggest that counterfactuals should be customary.

\subsection{Allocation}

There are two open issues here. One is allocating carbon burden to crop components by weight. This has led to the dubious practice of assigning the majority of a grain footprint to the straw that is grown along with the grain. Dubious yes, but it has been applied in numerous studies for the German government, only a few years ago, that the government then promoted.

The other is the allocation of $\mathrm{CO}_{2}$ capture, i.e. the removal of carbon dioxide from the atmosphere by photosynthesis. Why is the captured $\mathrm{CO}_{2}$ always allocated to a biofuel? Why 
cannot a fossil fuel take that carbon credit? Or should the credit be shared proportionately between the two? The answers here are not immediately obvious, but even more obvious is that the questions appear not to be asked in most studies - and yet they should be.

\subsection{Marginal/consequential modelling}

Simply put, current practice presumes that every additional unit of biogenic $\mathrm{CO}_{2}$ emitted is recycled to the biosphere via photosynthesis - from the earth to the earth. By contrast, every additional unit of fossil $\mathrm{CO}_{2}$ emitted stays in the atmosphere, creating more heat.

Yet as pointed out in the allocation discussion, this cannot make sense: carbon dioxide is carbon dioxide. Also, the ability of the biosphere to capture carbon can and does change, depending particularly on forest conditions and water-saturation levels. Once again, the answers here are not immediately obvious, but the questions should be addressed.

\subsection{Additionality and subtractionality}

The idea of additionality may be useful in creating accurate accounts of forest carbon. If a forest is planted on previously non-forested land, with the express intent of using the harvested trees as biofuel, then this might properly be considered as carbon neutral. Indeed, it probably is carbon negative: although carbon is being harvested, on a net basis, more carbon might be returned to the soil and the vegetation above.

Likewise, what about 'subtractionality'? If trees are being harvested for fuel that otherwise would have remained standing, their carbon surely should be removed from the forest's carbon stock, and debited against the footprint. The case for this has been made by (Rabl, Benoist et al. 2007), (Johnson 2009) and (Searchinger, Hamburg et al. 2009), but the term subtractionality - you first heard it here.

\section{Discussion and conclusions}

This paper has raised more questions than it has answered - and that is its intent. Without addressing these questions, carbon accounting will continue to be wildly inaccurate. And 'wildly' is no overstatement: the current discussion in CEN and ISO $^{3}$ of biofuel standards demonstrates how divergent current opinion is on these issues.

Getting more convergent opinion is important, and not just for the reputation of LCA and carbon footprint analysts, who often are cursed with the epithet of 'you can get any answer you want'. More convergence will be critical to investors, policy makers and the general public. If we really believe that reducing carbon emissions is critical to our future, the questions raised in this paper are worth serious exploration.

To conclude, there might be a simple principle to guide further research: efficiency is the key. The source of carbon is surely less important than the efficiency by which it is used. Moreover, efficiency also drives economics; efficient fuels generate the most consumer demand. Efficiency can and should guide the evaluation of future fuels, and the rules of carbon accounting should be constructed to promote this.

Put another way, the key to reducing atmospheric concentrations of carbon is to put less carbon up there in the first place and to keep more of it down here on the ground. We should

\footnotetext{
${ }^{3}$ The author is a delegate and part of the ongoing discussions.
} 
be more worried about how much net carbon is being emitted, and less worried about which kind of carbon, i.e. biogenic or fossil, is being emitted. If we use this simple concept as our guide, I think we will make much greater progress toward solving this great problem.

\section{References}

[1] Argonne Labs GREET, Greenhouse Gases, Regulated Emissions, and Energy Use in Transportation, Version 1.8c.

[2] Joint Research Centre of the EU Commission, EUCAR, et al. (2008). Well-to-Wheels analysis of future automotive fuels and powertrains in the European context.

[3] Searchinger, T. D., S. P. Hamburg, et al. (2009). "Fixing a critical climate accounting error." Science 326 (23 October 2009): 527-528.

[4] Rabl, A., A. Benoist, et al. (2007). "How to Account for $\mathrm{CO}_{2}$ Emissions from Biomass in an LCA." International Journal of LCA 12(5): 281.

[5] Johnson, E. (2009). "Goodbye to carbon neutral: getting biomass footprints right. ." Environmental Impact Assessment Review.

[6] Manomet Center for Conservation Sciences (2010). Massachusetts Biomass Sustainability and Carbon Policy Study: Report to the Commonwealth of Massachusetts Department of Energy Resources. Brunswick, Maine.

[7] Berntsen, T. and G. P. Peters (2010). $\mathrm{CO}_{2}$ perturbation and associated global warming potentials following emissions from biofuel based on wood. Greenhouse gas emissions from bioenergy systems: impacts of timing, issues of responsibility Brussels.

[8] Cowie, A. (2010). Is bioenergy really carbon neutral? Greenhouse gas emissions from bioenergy systems: impacts of timing, issues of responsibility Brussels.

[9] ISO (2006). ISO 14040: Environmental management — Life cycle assessment — Principles and framework.

[10]Heinen, R. and E. Johnson (2008). "Carbon footprints of biofuels \& petrofuels." Industrial Biotechnology 4(3): 257-261. 